\title{
Remote sensing of Carpathian flysch landslides with the use of terrestrial laser scanner
}

\author{
Janusz P. Kogut ${ }^{1,}$, and Ievgen Tymoshenko ${ }^{2}$ \\ ${ }^{1}$ Cracow University of Technology, Faculty of Civil Engineering, Cracow, Poland \\ ${ }^{2}$ National Mining University, Dnipro, Ukrainep
}

\begin{abstract}
Terrestrial laser scanning helps us to detect unstable subsurface behaviour, assessing the slope stability and potential landslide failure modes. If the slopes are regularly observed, the risk of slope movement and subsequent consequences may be considerably reduced. This allows for optimum land use conditions that are economically justified. Landslides in the Carpathian flysch have a peculiar susceptibility to activation due to the region's geological structure. This work addresses the problem of monitoring and analysing the effects of landslides associated with the operation of routes (roads and railway lines) running through the slopes of the Carpathian flysch. The terrestrial laser scanner enables site remote sensing in a simple and automated manner. Regular measurements with multiple scanner positions may be used for long term slope monitoring. A detailed geological structural model allows for risk assessment with regards to failure modes, and it allows for a slope stability assessment. The model, along with the substrate parameters, introduced into the Finite Element Analysis package enables an analysis of the effects of landslide susceptibility and the displacements of the terrain surface in time, as well as due to different loading cases.
\end{abstract}

Keywords: laser scanning, numerical modeling, landslide, Carpathian flysch, slope stability

\section{Introduction}

The Carpathian Mountains, known as the Carpathians, do not actually form a continuous chain of mountains. Rather, they consist of a number of orographic groups that belong to the Alps. The Carpathians, which do not exceed an altitude of 2,700 m, do not have snowfields or large glaciers. The Carpathians are separated from the Alps and the Balkan Mountains by the Danube River. The Carpathians are surrounded by plains on all sides, namely the Pannonian Basin to the southwest, the Moesian Plate to the south, and the Eastern and Western European plates to the north. Figure 1 presents the Carpathians and its surroundings. The Carpathian Mountains were formed during the Alpine orogeny in the Mesozoic and Tertiary by moving the plates over subducting oceanic crust. The mountains take the form of

\footnotetext{
*Corresponding author: jkogut@pk.edu.pl
} 
a fold and thrust belt with generally north vergence in the western part, northeast to east vergence in the eastern part and southeast vergence in the southern part. The external, generally northern, portion of the orogenic belt is a tertiary accretionary prism of the Carpathian Flysch Belt created by rocks scraped off from the sea bottom and thrust over the North-European plate [1]. The flysch is an alternating marine deposit of claystones, shales, and sandstones, which were detached from their substrate and transported several kilometres away. The northern slope of the Carpathians, located in Poland, is linked to the Baltic Sea by the drainage basins of the Vistula River. Larger rivers originating in the Carpathians include the Vistula, the Dniester, and several Danube tributaries. The Carpathian rivers are characterized by a rain-snow regime; high-water periods occur in the spring and in summer, the latter usually being more powerful. The floods sometimes have catastrophic dimensions caused by the poor ground retention of the rainfall. The rainfall may also trigger landslides.

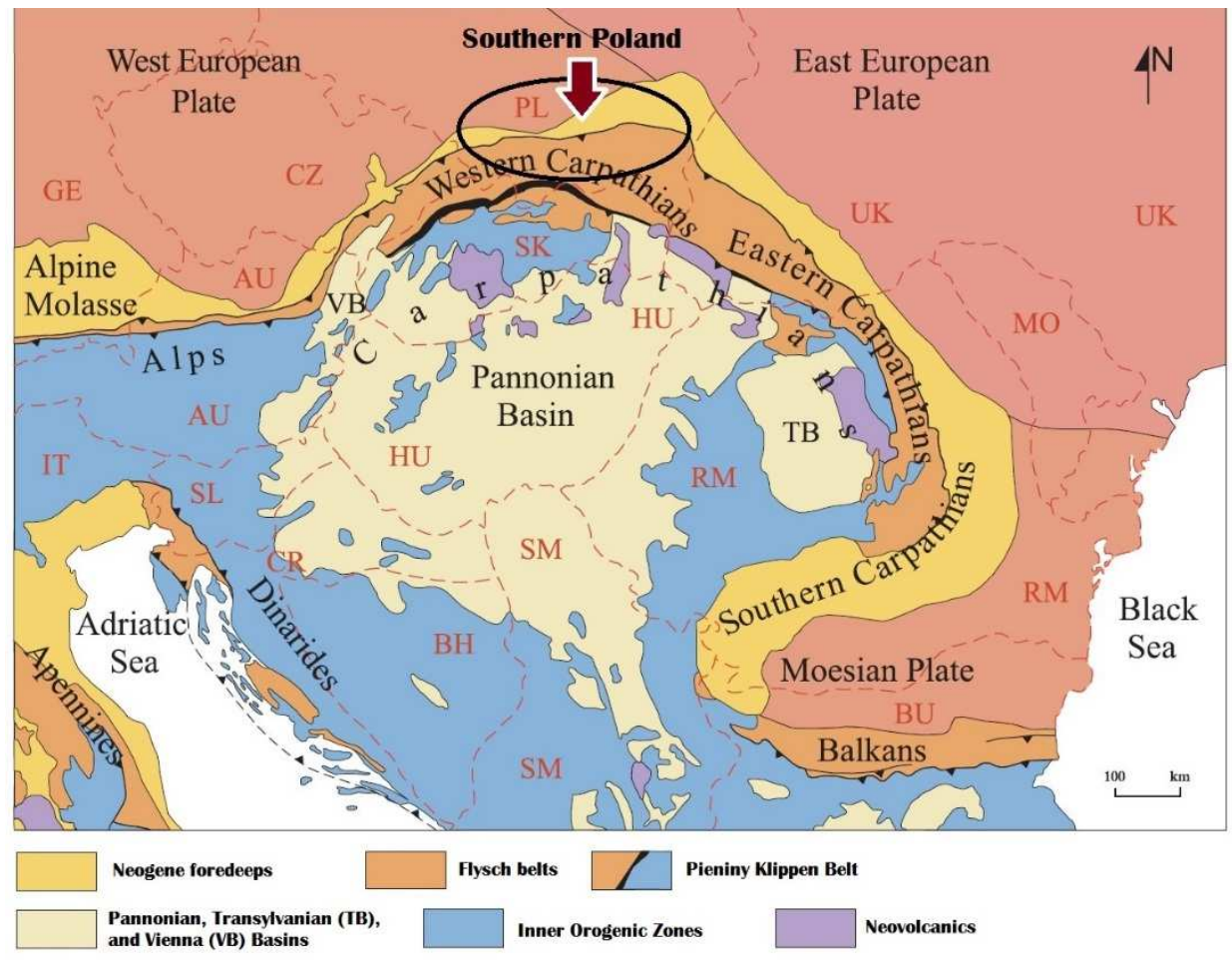

Fig. 1. The Carpathian Mountains and the surrounding plates [2].

In the Carpathians, which cover about $6 \%$ of Poland, about $95 \%$ of all landslides registered in Poland were identified and are currently being recorded. In the most susceptible regions of the Carpathians, about $40 \%$ of the area is covered by landslides or other forms of soil mass movements. It is estimated that, in this region of Poland, for every square kilometer of area and for every $5 \mathrm{~km}$ of the road infrastructure network, there is one landslide, on average [4]. The average slope of its mountains ranges from 15 to $35 \%$, and the deep slots of the area with valleys and significant differences in height are conducive to the formation or the activation of landslides. Figure 2 presents the southern part of Poland, indicating the places where the soil mass movements and landslides are observed, including two landslides analysed in this paper. 


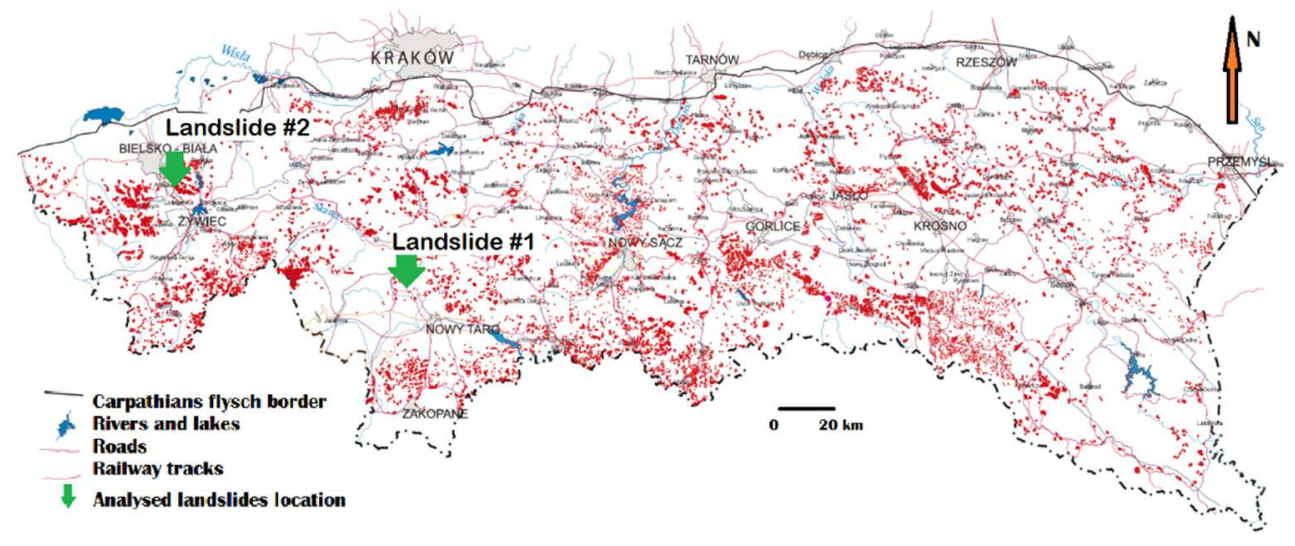

Fig. 2. Landslides in the southern part of Poland [3].

\section{Survey of the retaining structure with the damaged section}

The terrestrial laser scanning is a modern terrain mapping method. The measurements are based on recording a laser beam, which is reflected from different objects. The signal, registered by the unit, is converted into an electric one and then is subjected to further digital processing. Due to the waveform analysis, and when signal reaches the receiver, the calculations are performed for the signals reflected in time intervals, for the subsequent reflecting objects. For the known light beam velocity and its run time from the source to the receiver, the distance between the scanner and the reflecting body is determined. The high frequency wave emitted is by scanner is equal to $\mathrm{f}=122 \mathrm{kHz}$ [5]. The mapping of the scanned area obtained is then transformed to the Cartesian coordinates $(\mathrm{x}, \mathrm{y}, \mathrm{z})$. The data set as the form of a point cloud, creates an image of the scanned space. The measured space data is then archived for further processing. The difficulty in the laser recording processes is the vast amount of data. Therefore, the crucial parts of the area are combined data from various measurement stands. The removal of unwanted objects (particularly trees, shrubs, fences, etc.) is necessary and influences the simplicity of the scanned relief of the area. The measurements were taken in so called 'long scan mode', which is characterized by maximum resolution. As a part of the surveying work, a local situation and altitude map of the landslide was made using a Riegl Vz-400 terrestrial laser scanner [6]. The scanner has high speed data acquisition with up to 500,000 measurements $/ \mathrm{sec}$, with a wide field of view $100^{\circ}$ over $360^{\circ}$. It has a range of measurements up to $800 \mathrm{~m}$, with $5 \mathrm{~mm}$ accuracy and a precision of measurements about $3 \mathrm{~mm}$. The ordinates were determined using a method of direct survey in the field in the local coordinate system.

The research area is located in the active part of the landslide \#1 [7]. Therefore, the section of the provincial road located along this area is at risk. The as-built inventory shows that the sections of the retaining structure have been visibly dislocated. The displacement is clearly visible in the upper part of the plate and measures $8 \mathrm{~cm}$ horizontally and $3 \mathrm{~cm}$ vertically. Figure 3 presents a picture of the damaged slab section of the anchored retaining structure from different perspectives, taken during the summer and winter measurement campaigns. 


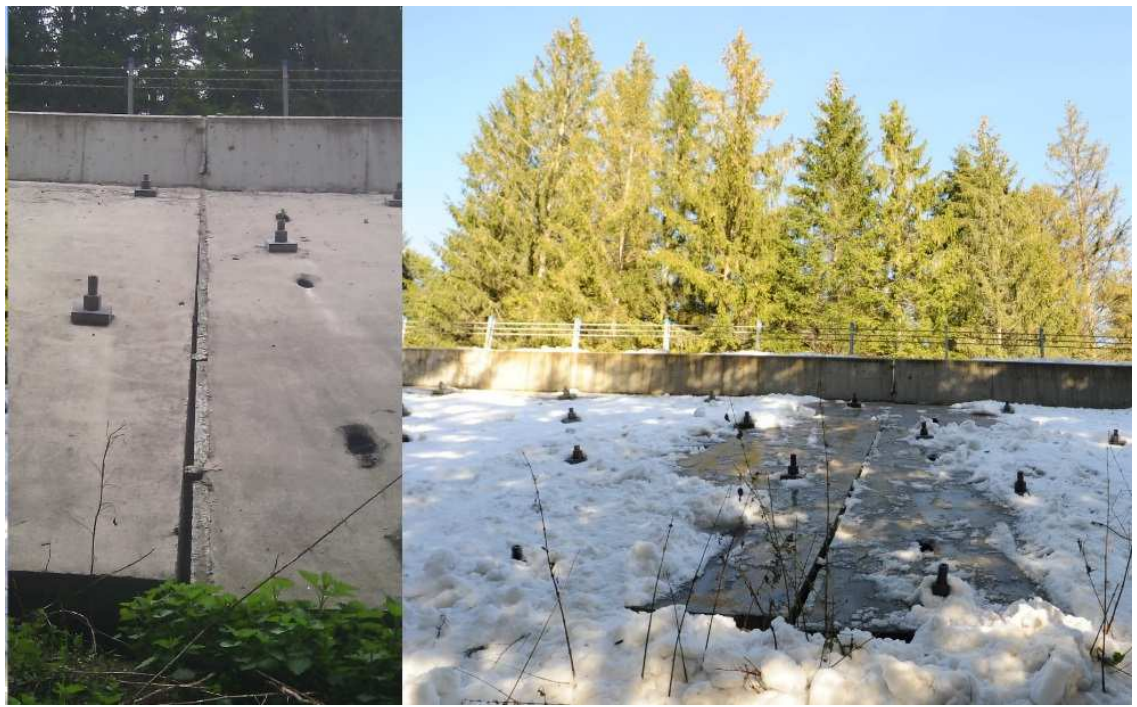

Fig. 3. Retaining structure with the damaged slab section (photo by authors).

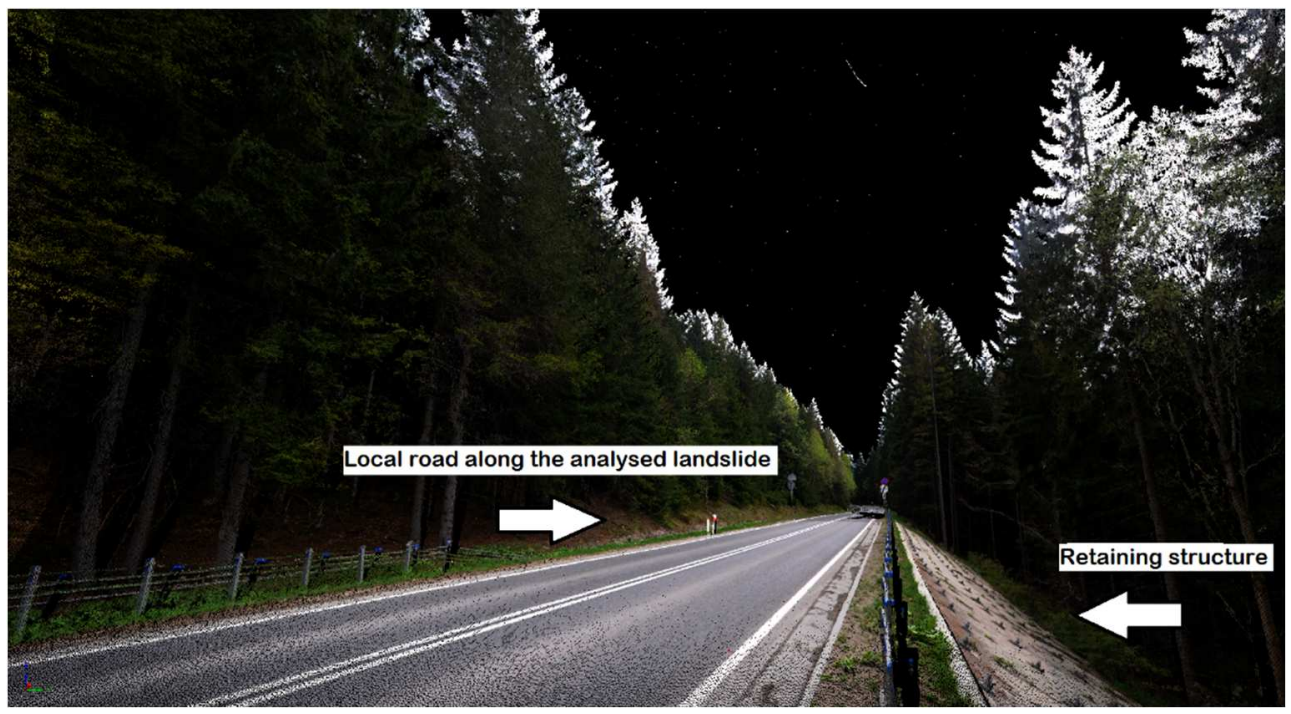

Fig. 4. 3D laser scan of the road and the retaining structure (own elaboration).

Figure 4 shows a terrestrial laser scan of the site. It displays an image of the road and the landslide stabilized by the retaining structure. The image was prepared using the RiScan PRO software package on a stretch of 75 meters [8]. The data set, in the form of a point cloud, creates an image of the scanned space. It illustrates the research area described here. The measured space data were then archived for further processing. The image obtained, in the form of a cloud of points, may be compared with subsequent scans in order to monitor landslide movements. The factors influencing measurement quality deterioration include precipitation resulting in disturbances in the cloud of points. Figure 5 displays the differential scan of the total displacements of the surface of the damaged section of the retaining wall. The intersection is still under the investigation and the results of two consecutive scans visible in figure 5 were performed within 6 months. 


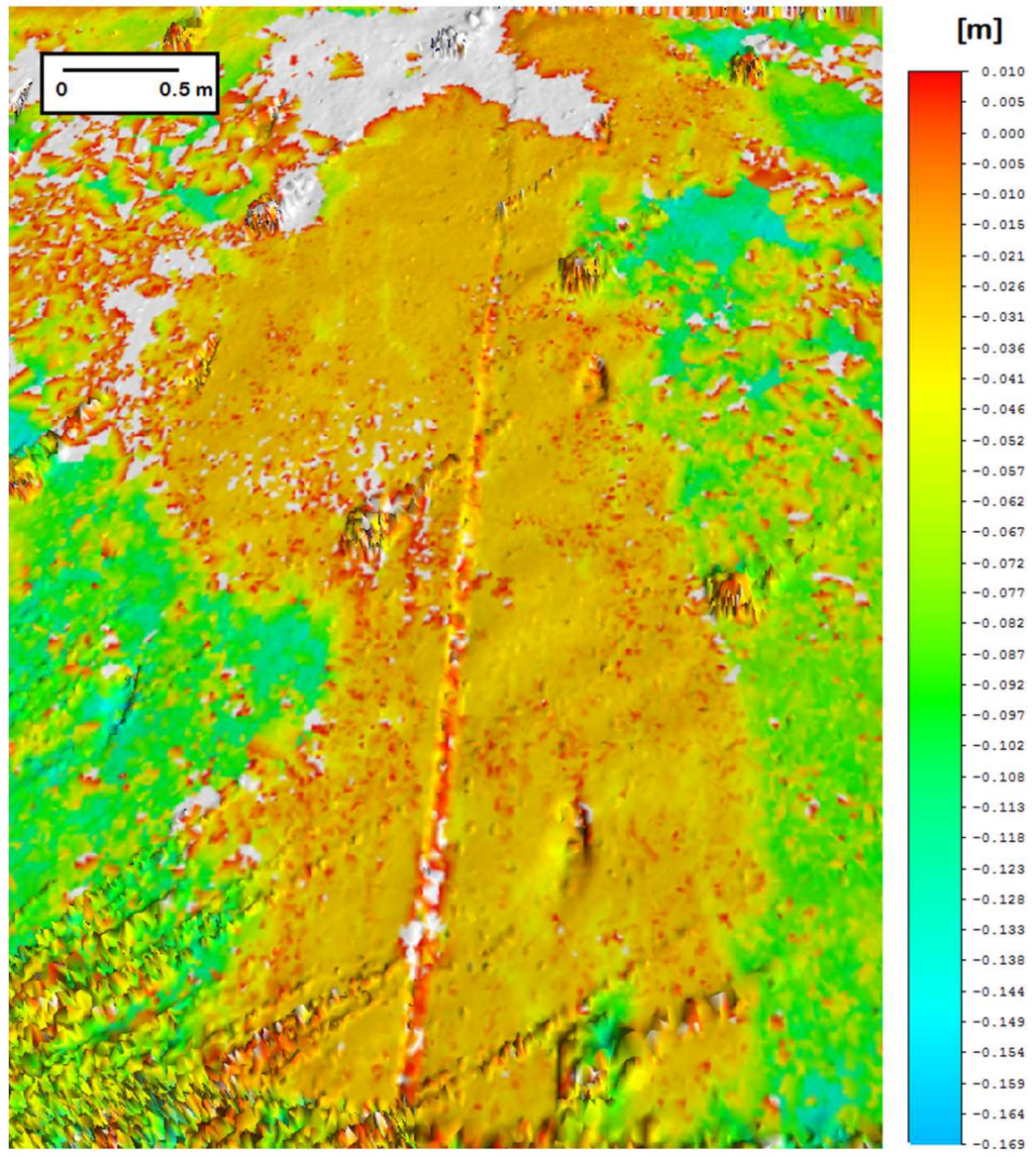

Fig. 5. Differential model of the total displacements of the surface of the analysed sections of the retaining wall visible in fig. 3 (own elaboration).

A terrestrial laser scanner survey allowed us to apply the cloud map of the terrain to the numerical 3D model. Figure 6 presents the surface of the analysed slope with the road and the retaining structure extracted from the scan. The surface was then introduced into the FEA package [9]. There are various slope stability analysis methods. Strength Reduction Method (SRM) is a non-linear method based on the limit equilibrium theory [10]. It analyses the minimum safety factor and failure behaviour using various shapes, loads, and boundary conditions. The SRM may be used to simulate the failure process without any previous assumptions and may be applied to 3D problems. The SRM method gradually decreases the shear strength and internal friction angle until the calculation does not converge; the obtained point is considered to be the failure point of the slope. The maximum shear strength reduction ratio, at that point, is used to calculate the minimum safety factor of the slope. Stability by SRM is achieved by weakening the soil in an elastic-plastic discrete analysis until the slope fails. The Factor of Safety is considered to be the factor by which the soil strength is to be reduced to reach failure. 


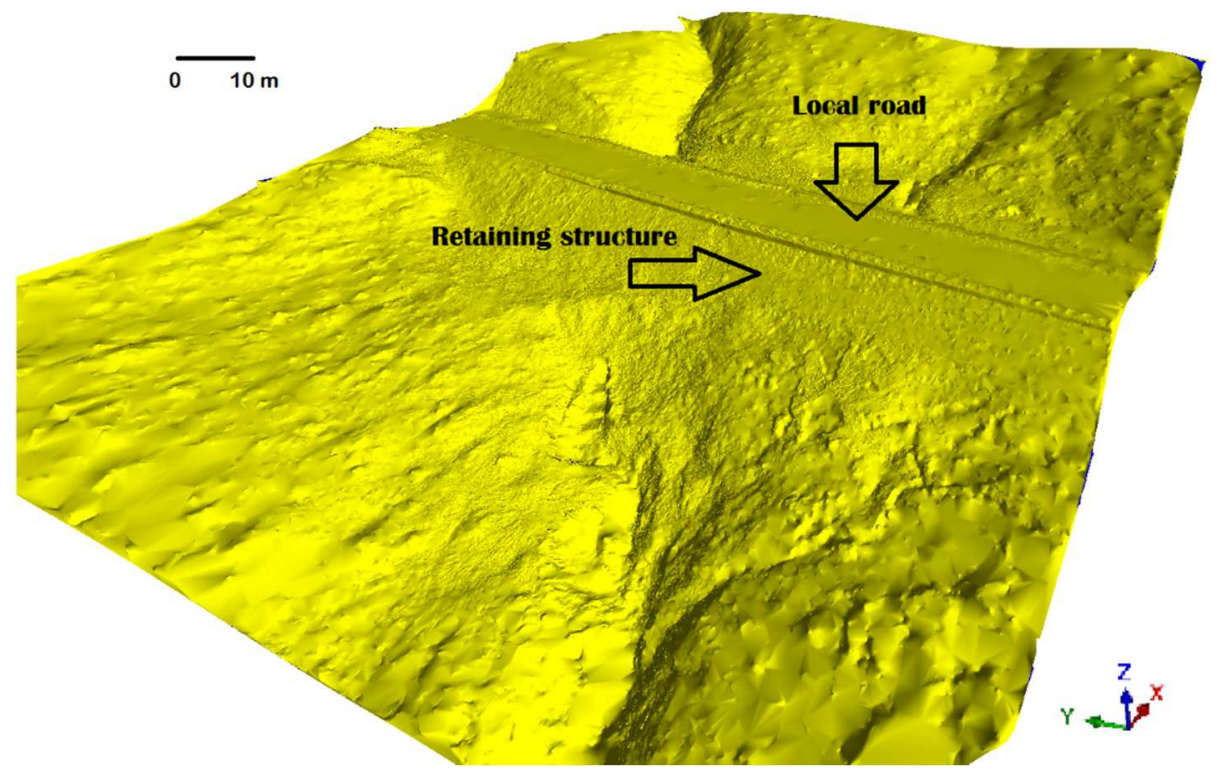

Fig. 6. 3D surface scan (own elaboration).
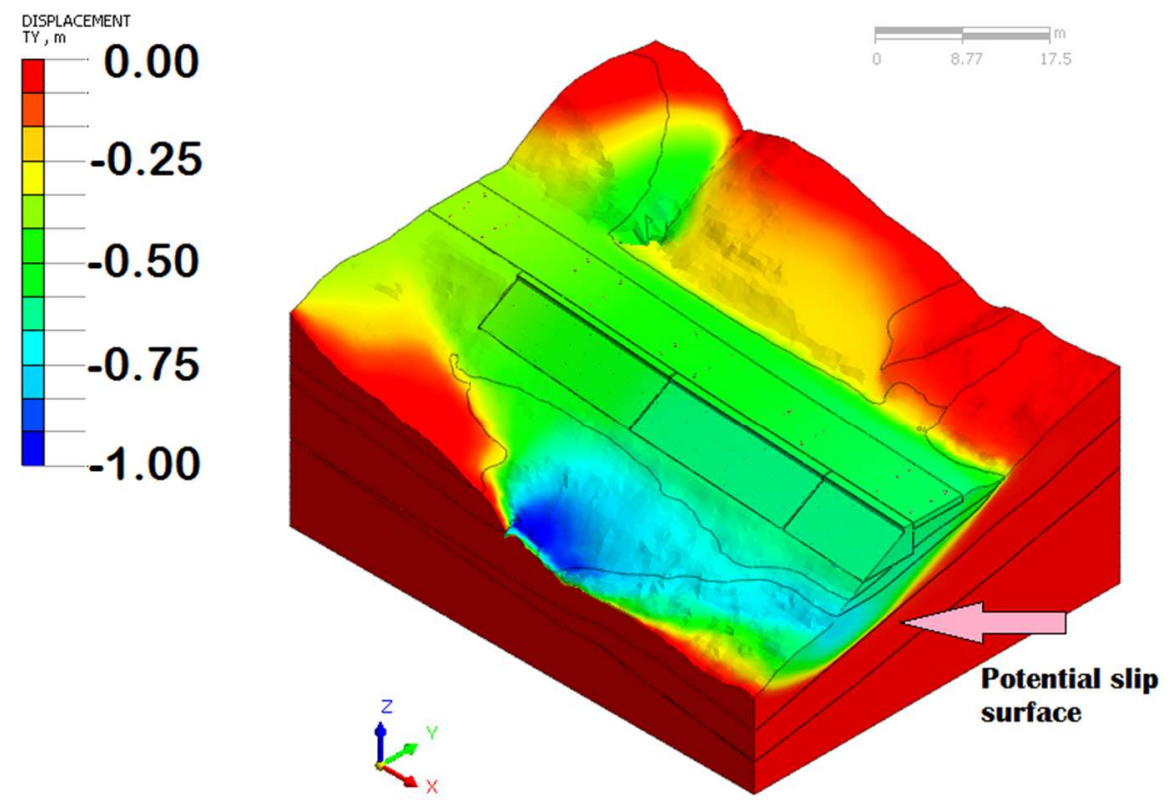

[DATA ] FOS, Slope Stability(SRM), INCR $=15$ (FOS $=1.4563$ ), [ UNIT ] N, m

Fig. 7. 3D FEM model of the slope exhibiting horizontal displacements with a potential slip surface (own elaboration).

Figure 7 presents the FEM model of the slope with a slip surface computed using SRM. The FEM model included pre-stressed anchors mounted in the cross-section. Potential slip surface is indicated in figure 7, where the essential part of the terrain visible in figure 6 is used to create a real 3D map, while the subsurface data is taken from the geological prospection. More elaborated results of the FEM study and their discussion has already been done [7] and it is not presented here. 


\section{A route with the noise barrier and the retaining wall}

The next example analyses the cross-section located in the area of the Carpathian flysch (landslide \#2). The situation presented in this chapter focuses on forecasting an extreme threat, especially in current climate changes. It demands a detailed recognition of soil conditions to an appropriate level below the ground and diagnosing the occurrence of one or more potential slip surfaces.

Quaternary deposits recognized here are composed of silty soils - silty clays, and clays on the layer of debris. Below it, the Magura sandstone is present. The groundwater table is variable, and it is located $2 \mathrm{~m}$ below ground level. There is a single-family dwelling house located on the hill slope. It is considered to be an additional load on the site. Figure 8 displays the differential scan of total displacements of surface model in the natural conditions of the slope. The results of two consecutive scans visible here were performed within 6 months during the autumn and spring measurement campaigns.

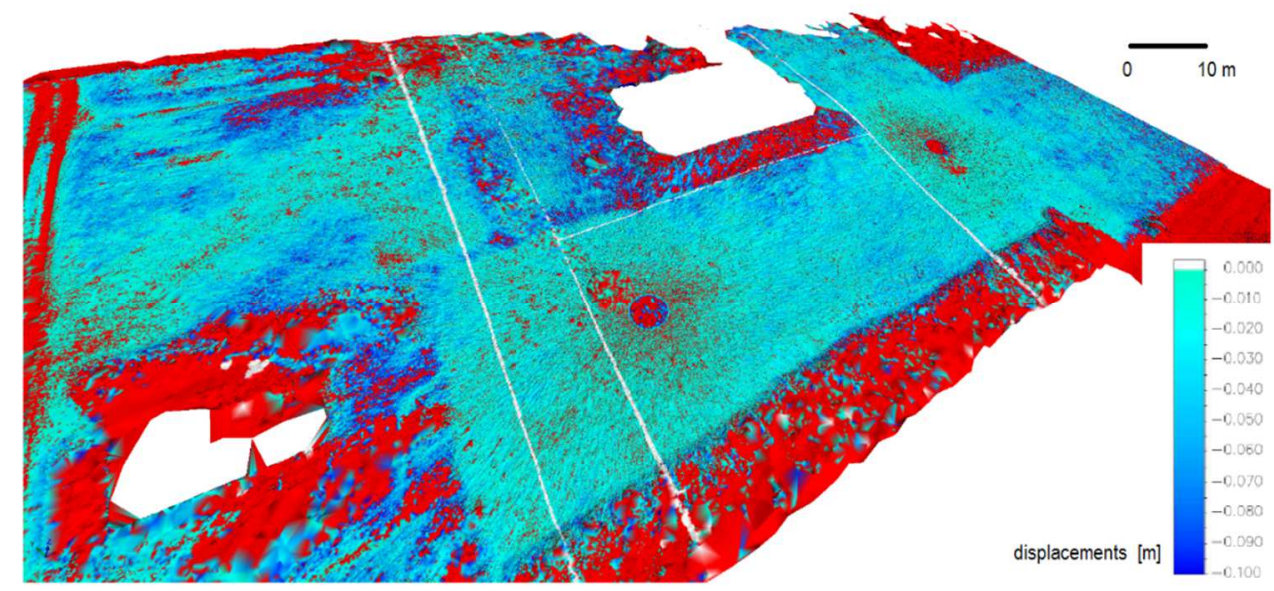

Fig. 8. Differential model of the surface of the analysed case (own elaboration).

In the vicinity of the slope, a dual expressway was planned and built, along with a noise barrier located within the traffic lane. Therefore, earthworks were carried out involving the removal of the overburden soil and the construction of the escarpment. Figure 9 presents the overview of the slope with the retaining structure and noise barriers. The results of the analysis indicate the impact of the road excavations on reducing the stability of the built-up slope. Numerical calculations showed that the slope stability factor with the excavation made is about $15 \%$ smaller than the slope stability factor without excavation. The results concern only the dry slope. An additional destabilizing factor may be the groundwater table rise. The groundwater reduces the stability factor by about $20 \%$ [11]. This means that an excavation of the road and raising the groundwater level increases the threat to the road infrastructure. 


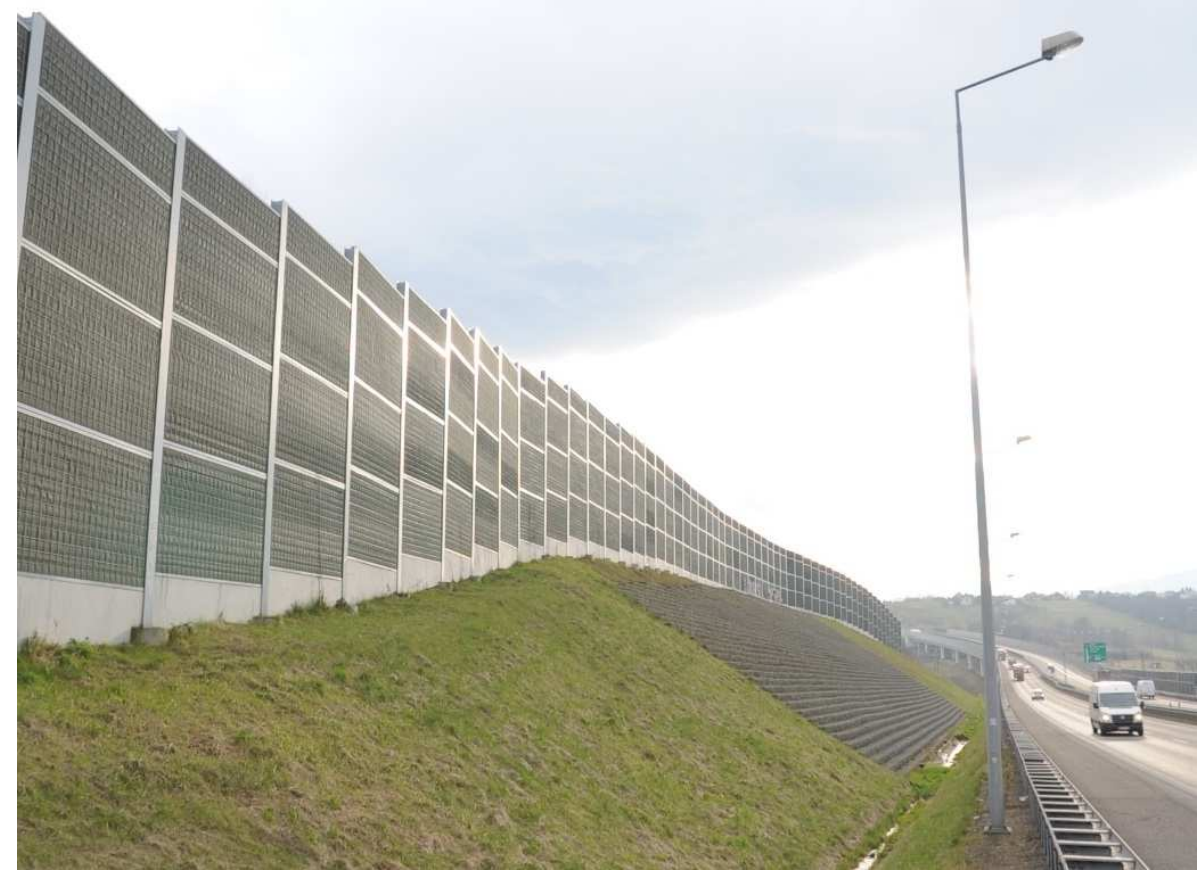

Fig. 9. Overview of the slope with retaining structure and the noise barriers (photo by authors).

The Carpathian flysch is a difficult subgrade to design roads due to its complicated soil conditions and the landslide threat. Very often, the first slip surface is located on the border of the weathered zone of the flysch and the rock [12], as it turned out to be in this considered case. The built-up scarp presented here has failed, as a result of a road excavation in complicated soil conditions during the construction process. Hence, the construction of a retaining structure has become crucial. It was built during a period of unfavorable weather conditions, including heavy rains. The situation presented here concerns forecasting an extreme threat, especially in the current climate changes.

Figure 10 presents the differential model of the slope with the retaining structure and noise barriers. The displacements of the slope are visible only in the behaviour of the noise barriers. It seems to be stable with small vertical settlements around the retaining structure. The retaining structure measurements are not credible regarding the fact that the aggregate has been disintegrating due to weathering process.

In Figure 11 the FEM numerical model of the slope with the retaining structure and noise barriers is visible. The total displacements of the noise barriers located on the slope are similar to those registered by the terrestrial laser scanner. Also in this case the slope is still under the investigation. 


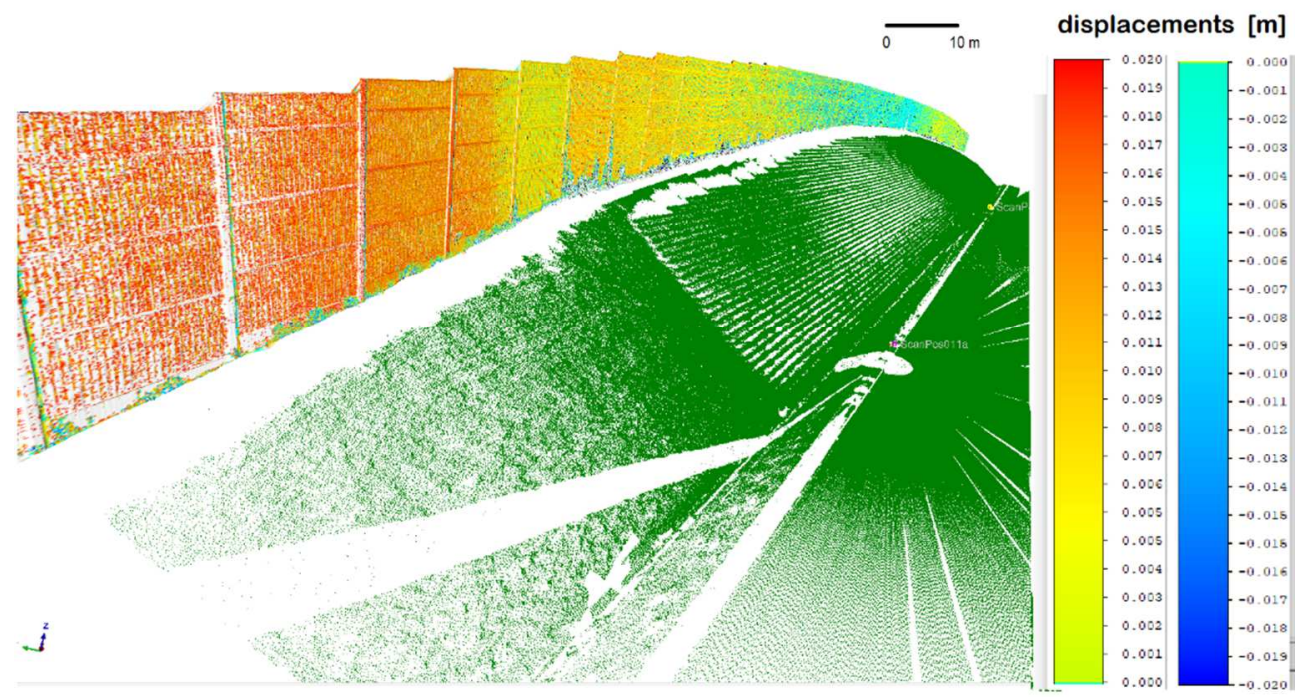

Fig. 10. Differential model of the slope with retaining structure and the noise barriers (own elaboration).

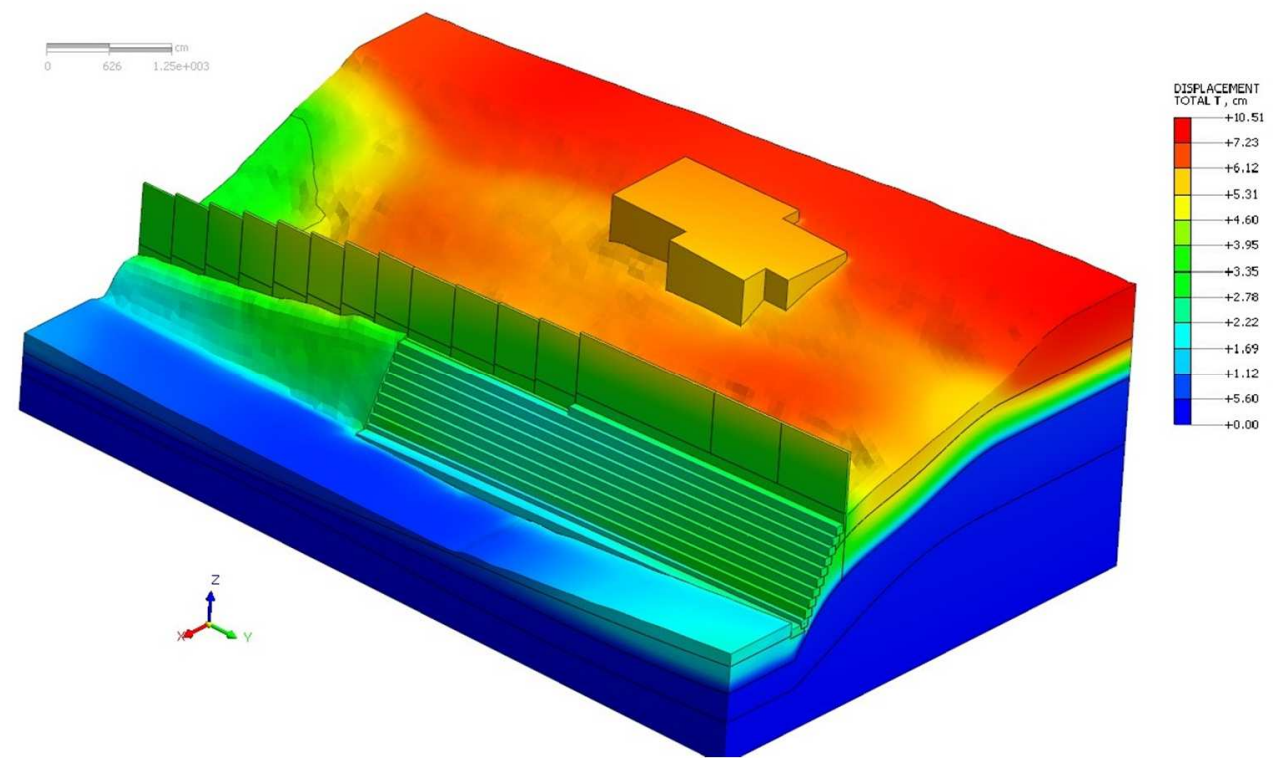

Fig. 11. The total displacements of FEM model of the slope with retaining structure and the noise barriers (own elaboration).

\section{Final remarks}

This work presents the results of laser scanning in the Carpathian flysch conditions. It may help to evaluate the usefulness of the method for monitoring the deformations on the terrain surface over the potential slip surfaces. The measurement results, taken from two sites and carried out over several months, indicated possible existence of the local landslide threat even after stabilization works. However, the deformations found are rather small and cannot be 
dangerous for the nearby road infrastructure. The obtained results prove the usefulness of terrestrial laser scanning to recognize discontinuous deformations of the terrain surface in such harsh soil conditions. They are a starting point in the discrete analyses of slope stability as visible in two analysed cases, illustrated by the results of FEM analyses. They can also be used to assess the causes of damage to buildings associated with landslide activity.

\section{References}

1. N. Oszczypko, Late Jurassic-Miocene evolution of the Outer Carpathian fold-and-thrust belt and its foredeep basin (Western Carpathians, Poland), Geol. Quart., 50 (1): 169194 (2006)

2. J. Golonka, F.J. Picha. The Carpathians and their foreland: Geology and hydrocarbon resources. AAPG Memoir 84, ISBN-10: 0891813659, ISBN-13: 978-0891813651 (2006)

3. D. Poprawa, W. Rączkowski, Landslides of the Carpathians, Przegląd Geologiczny 51, 8, 685-692 (2003) (in Polish)

4. L. Bober, L. Thiel, L. Zabuski, Landslide phenomena in Polish flysch Carpathians. Geological and engineering properties of selected landslides, IBW PAN Gdańsk (1997) (in Polish)

5. E. Pilecka, D. Szwarkowski, An application of the ground laser scanning to recognise terrain surface deformation over a shallowly located underground excavation, E3S Web of Conferences, vol. 24 (2017), DOI: 10.1051/e3sconf/20172401006

6. www.riegl.com

7. E. Pilecka, J. Kogut, D. Szwarkowski, Analysis of landslide effects along a road located in the Carpathian flysch. Open Geosciences, 10 (1): 517-531 (2018), DOI:10.1515/geo2018-0041

8. RiScan PRO Manual. Mena3D GmbH, Stuttgart, Germany (2014)

9. MIDAS GTS NX, Manual specifications (2016)

10. D. Grifiths, P. Lane, Slope stability analysis by finite elements. Géotechnique, 49(3), 387-403 (1999), DOI:10.1680/geot.1999.49.3.387

11. E. Pilecka, J. Kogut, Soil mass movements as threats to the road transportation infrastructure, TTS, Technika Transportu Szynowego. Koleje, Tramwaje, Metro, 12, 2825-2830 (2015), ISSN 1232-3829, (in Polish)

12. P. Harba, Z. Pilecki, Assessment of time-spatial changes of shear wave velocities of flysch formation prone to mass movements by seismic interferometry with use of ambient noise. Landslide 14 (3): 1225-1233 (2017), DOI: 1007/s10346-016-0779-2 